\title{
Assess the Level of Assertiveness among BSc Nursing Final Year Students in a Selected Nursing College, Chennai, Tamil Nadu, India
}

\author{
C Sumathi ${ }^{1}$, J Van Vagula Devi ${ }^{2}$, V Prathiba Sivakumar ${ }^{3}$
}

\begin{abstract}
Background: Assertiveness in nursing is the important footstep in the ladder of professional progress. Assertiveness is a healthy behavior and valuable component in nursing profession, which is beneficial to nurse, client, other workers, and community in large. Being assertive will also increase the visibility in nursing.

Materials and methods: The quantitative research approach, nonexperimental, descriptive research design was adopted among 30 BSc Nursing final year students at Venkateswara Nursing College using improbability convenient sampling technique for the study. The demographic data and the 3-point rating scale to assess the level of assertiveness were used to collect the data from the students. The rating scale consisted of 20 items. The collected data were organized, tabulated, analyzed, and interpreted by using descriptive statistics and inferential statistics.

Results: The results showed that $10 \%$ of students had moderate level of assertiveness and $90 \%$ of students had adequate level of assertiveness. There was a significant association between the gender and number of siblings with the level of assertiveness at $p<0.05$ level.

Conclusion: It is crucial that nurses and students develop assertiveness skills so that they can provide safe and effective care for patients. As nurse works in different situations, they have to be assertive in order to meet the challenges and to win the cooperation from others.

Keywords: Assertiveness, Assess, Knowledge, Nursing personnel.

Pondicherry Journal of Nursing (2020): 10.5005/jp-journals-10084-12159
\end{abstract}

\section{INTRODUCTION}

\section{Background of the Study}

Assertiveness is essential to nursing profession in many ways. Nursing profession is the respectful profession which demands and shows respect for others. ${ }^{1}$ Assertive ways of communicating and putting one's own concerns, ideas in front of others which help to the clients care as well as for nursing profession itself. Assertive nurse defends client in every aspect. It enhances honesty and dedication in the nursing profession. Assertiveness is a broad term associated with the individual from hierarchical development of life. It adds to the quality of life by adding meaning and support to one's behavior. ${ }^{2}$ It is not only being confident about one's words but also about one's actions, doing, and behavior exhibited in every situation of life. It is learned behavior or mode of communicating feelings, ideas in a confident way without being aggressive on others. It depicts the confident behavior in an individual within underestimating the others. Being assertive is beneficial to everyone. It can be defined simply, to convey one's own point of view which affirms the right of the individual without violating the rights of the other person.

Assertiveness is the way of expressing one's feelings, opinions, beliefs, and needs openly and honestly, without violating the rights of others. Assertive staff nurses are able to suggest their views clearly and accepts and takes criticism positively, respects the rights and responsibilities in a nursing situation and act accordingly. Lack of assertiveness results in ineffective communication thus compromising quality patient care. If suppose, the patients identify the lack of assertiveness in nurses, they do not develop trusting relationship with them. Assertive nurses empower their patients and build confidence in whatever the care provided. ${ }^{3,4}$

Developing assertiveness and communication skills should be started in the nursing education programs, where students
'Department of Obstetrics and Gynaecological Nursing, Venkateswara Nursing College, The Tamil Nadu Dr MGR Medical University, Thalambur, Chennai, Tamil Nadu, India

${ }^{2}$ Department of Community Health Nursing, Venkateswara Nursing College, The Tami INadu Dr MGR Medical University, Thalambur, Chennai, Tamil Nadu, India

${ }^{3}$ Department of Medical Surgical Nursing, Venkateswara Nursing College, The Tamil Nadu Dr MGR Medical University, Thalambur, Chennai, Tamil Nadu, India

Corresponding Author: C Sumathi, Department of Obstetrics and Gynaecological Nursing, Venkateswara Nursing College, The Tamil Nadu Dr MGR Medical University, Thalambur, Chennai, Tamil Nadu, India, Phone: +91 9884081371, e-mail: sumiebi16@gmail.com

How to cite this article: Sumathi C, Devi JVV, Prathiba Sivakumar V. Assess the Level of Assertiveness among BSc Nursing Final Year Students in a Selected Nursing College, Chennai, Tamil Nadu, India. Pon J Nurs 2020;13(2):33-36.

Source of support: Nil

Conflict of interest: None

are allowed to express their opinions and personal rights with the hopes of encouraging empowerment and enhancing autonomy. Classroom teachings are not sufficient to develop clinical practice. Therefore, practical skills can be imparted using various methods of teaching, such as demonstration, role play, and experience in clinical lab, so that the students can receive guidance, motivation, and feedback from the nursing faculty. The teachers should also ensure a conducive environment for the students to practice their skills in order to evaluate and get feedback. ${ }^{5}$ 


\section{Need for the Study}

Assertive individuals are able to express and respond to their positive and negative feelings without anxiety and unnecessary anger. ${ }^{6}$ Assertiveness is necessary for effective nurse/patient communication, and it is suggested that its development may also aid the confidence of the profession as it develops.

Assertiveness and nursing are very closely related to each other. Nursing practice cannot be declared good if a nurse is not assertive. The assertiveness can be visualized in nursing care given by the nurse. Nurse has to be assertive enough in order to preserve rights of nurse as well as for clients who is seeking the nursing care. Assertiveness by a nurse shows a behavior that is based on certain principles, such as equality, respect, responsibility, and accountability. Being assertive, nurse is not being selfish rather it promotes the rights of the client, fairness, and equality in job description and most important efficiency and effectiveness of nursing practice is being attained. Nursing is a teamwork with other nurses and that can be attained by assertiveness. ${ }^{7,8}$ Nurses play a different role in healthcare setting:

- Healthcare team member

- Advocate

- Collaborator

- Leader.

To perform all these diverse roles effectively, she has to be assertive. The main aim of nursing care is to develop trust and interpersonal relationship, in order to promote the client's progress and build nurse-client relationship, assertiveness is required. Assertive nurse always possess confidence, good listening, not messy. ${ }^{9-11}$ The nurse must be always assertive while performing her duties and hand over charges to other health professionals.

Assertiveness plays a vital role in enhancing the professional growth. Assertiveness is a healthy behavior and a key component in the nursing profession which are beneficial to the nurse, client, other workers, and community in large. Being assertive will also reflect the image of nursing to the public. ${ }^{12}$

Mushtaq conducted a study to find the assertiveness in nursing at SKIMS Nursing College, Srinagar, India concluded that the assertiveness training should be included from the beginning. A complete assertiveness training program should be incorporated in the nursing curriculum. Being assertive during the course of study will enhance truthfulness, confidence while working as a staff nurse. ${ }^{13}$

Larijani et al. (2017) conducted a study to assess the assertiveness and the factors affecting it among nursing students. This was a descriptive cross-sectional study. Sixty-eight male and 105 female (173 participants) nursing students were selected respectively by census and quota sampling in 2007. The data were collected by personal-social questionnaire and assertion inventory (Al) of Gambrill and Richy. The data were analyzed by descriptive and inferential (Spearman test, Kruskal-Wallis test, Mann-Whitney test, stepwise multiple regression test) statistical tests. The results showed that $71.1 \%$ of the students had different degrees of deficit in assertiveness. The meaningful participation in the process of decision-making in family and working beside education $(p<$ 0.01 ), and relation was found between assertiveness and year of education $(p<0.04)$, working beside education (0.05). Also, there was a meaningful and reverse relation between assertiveness and age $(p<0.04)$. From different variables, age and participation in the process of decision-making in family had the most effect on the level of assertiveness. Since a good majority of students had deficit in assertiveness, performance of some educational plans about assertiveness is required during the nursing educational period. ${ }^{14}$

Miller conducted a study to assess the assertiveness in nursing students focused on that there was minimal evidence on whether or not nursing students become more assertive throughout their academic education. The purpose of this study was to compare the assertiveness scores of sophomore-level nursing students and senior-level nursing students. The study was guided by Hildegard Peplau's theory of interpersonal relations in nursing, which focuses on the therapeutic process between nurses and patients, rather than on internal patient pathology. The descriptive, comparative study used a 15-question survey design and a convenience sample of sophomore- and senior-level nursing students at a large urban Midwest University. Recruitment, informed consent, and data collection occurred during the sophomore and the senior classes. An independent sample $t$ test was used to determine group differences in assertiveness. The results revealed that the sophomore-level students were more assertive than the seniorlevel nursing students. ${ }^{15}$

Deltsidou conducted a study to assess the assertiveness level of nursing students throughout their training curriculum. The study population was composed of nursing students in different semesters at one school in Central Greece $(n=298)$ who agreed to complete a questionnaire on assertiveness level assessment. All students present in the class completed the questionnaire, representing $80 \%$ of the total population of active students. Mean assertiveness scores between semesters were compared by ANOVA and comparisons between the responses of the first-semester students and responses of advanced semester students were performed by Pearson's Chi-square. The main finding of this study was that the assertiveness levels displayed by students increase slightly in advanced semesters by comparison to those displayed by the first-semester students. Assertive behavior should be encouraged through learning methods. Nurses should preferably obtain this training throughout their studies. Instructors have an essential role in the improvement and achievement of assertiveness training curriculums for undergraduate nursing students. ${ }^{16}$

\section{Statement of the Problem}

A study to assess the level of assertiveness among BSc nursing final year students in a selected nursing college, Chennai.

\section{Objectives of the Study}

- To assess the level of assertiveness among BSc nursing final year students.

- To find out the association between the level of assertiveness among BSc nursing final year students with their selected demographic variables.

\section{HyPOTHESES}

- H1: To assess the level of assertiveness among BSc Nursing final year students.

- H2: There is a significant association between the levels of assertiveness among BSc nursing final year students with their selected demographic variables.

\section{Materials and Methods}

The sample consisted of 30 BSc nursing final year students. The study was conducted at Venkateswara Nursing College. A self- 
Table 1: Frequency and percentage distribution of demographic variables of BSc nursing final year students

\begin{tabular}{|c|c|c|c|c|}
\hline S. no. & Demographic variables & Class & No. of respondents & Percentage \\
\hline \multirow[t]{3}{*}{1} & Age in years & $18-20$ & 26 & 86.7 \\
\hline & & $21-23$ & 3 & 10.0 \\
\hline & & $>23$ & 1 & 3.3 \\
\hline \multirow[t]{2}{*}{2} & Gender & Male & 6 & 20 \\
\hline & & Female & 24 & 80.0 \\
\hline \multirow[t]{3}{*}{3} & Marital status & Married & 3 & 10.0 \\
\hline & & Unmarried & 27 & 90.0 \\
\hline & & Divorced & 0 & 0.0 \\
\hline \multirow[t]{3}{*}{4} & Race & African & 1 & 3.3 \\
\hline & & Indian & 29 & 96.7 \\
\hline & & Others & 0 & 0.0 \\
\hline \multirow[t]{3}{*}{5} & Religion & Christian & 7 & 23.3 \\
\hline & & Hindu & 23 & 76.7 \\
\hline & & Muslim & 0 & 0.0 \\
\hline \multirow[t]{4}{*}{6} & Language & Tamil & 26 & 86.7 \\
\hline & & Telugu & 2 & 6.7 \\
\hline & & Hindi & 1 & 3.3 \\
\hline & & Others & 1 & 3.3 \\
\hline \multirow[t]{2}{*}{7} & Interest in studying nursing & Yes & 23 & 76.7 \\
\hline & & No & 7 & 23.3 \\
\hline \multirow[t]{3}{*}{8} & Level of prior education & High school certificate & 26 & 86.7 \\
\hline & & Intermediate or post-high school diploma & 2 & 6.7 \\
\hline & & Institutional training & 2 & 6.7 \\
\hline \multirow[t]{3}{*}{9} & Siblings & One & 15 & 50.0 \\
\hline & & Two & 10 & 33.3 \\
\hline & & Above two & 5 & 16.7 \\
\hline \multirow[t]{2}{*}{10} & Type of family & Nuclear family & 20 & 66.7 \\
\hline & & Joint family & 10 & 33.3 \\
\hline
\end{tabular}

administered questionnaire was constructed after guidance from experts in the field of nursing. The tool has two sections: Section Aconsists of demographic data, such as age, gender, marital status, race, religion, language, interest in studying nursing, level of prior education, siblings, type of family and Section B-consists of selfadministered structured questionnaire with 20 questions to assess the level of assertiveness among BSc nursing students. It has been scored as adequate, inadequate, and moderately adequate. The formal permission was obtained from the Principal of Venkateswara Nursing College. The study was conducted among 30 BSc nursing students who met the inclusion criteria were selected using nonprobability convenient sampling technique. The sample was seated comfortably and a brief introduction about the investigator and study were given. Written and oral consent were taken from the sample; confidentiality of responses was assured till the end of the study. The questionnaires were given to the sample, explained about the question and the data were filled by the sample. Time spent for data collection in each sample was 20-30 minutes.

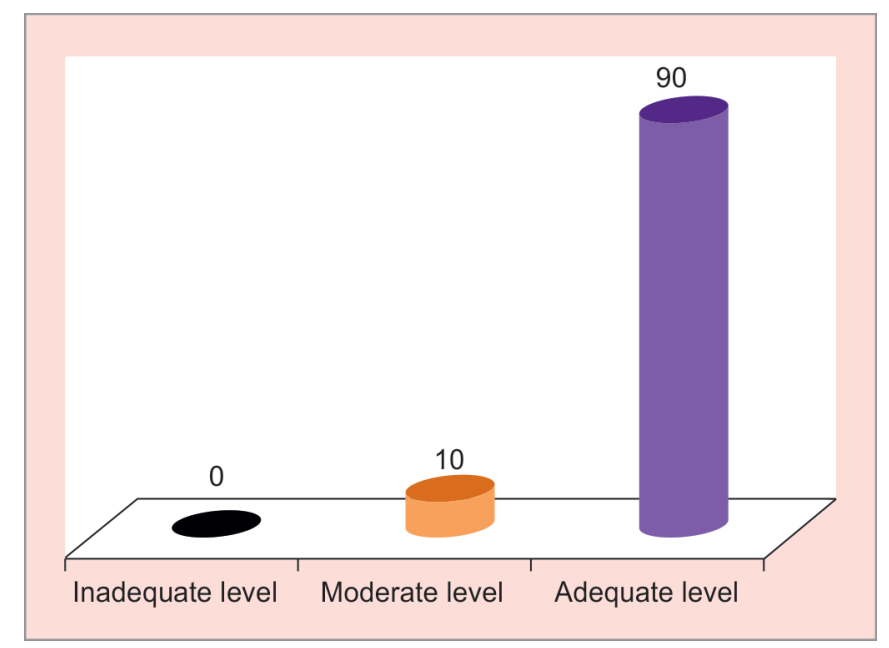

\section{Results and Discussion}

The demographic data revealed that majority of the students (86.7\%) belonged to $18-20$ years, $80 \%$ were females and $90 \%$ were unmarried. In regard to race, $96.7 \%$ were Indians, $76.7 \%$ belonged to Hindu religion, $86.7 \%$ were speaking Tamil, $76.7 \%$ students had interested in studying nursing, $76.7 \%$ had higher

Fig. 1: Percent distribution of level of assertiveness

secondary school education, $50 \%$ students had one sibling, and $76.7 \%$ belonged to nuclear family (Table 1 ). Ninety percent of the respondents had adequate level of assertiveness and $10 \%$ had moderate level of assertiveness (Fig. 1). There was significant association between the gender and number of siblings with the level of assertiveness. 


\section{Conclusion}

From this study, the researcher found that the assertiveness is considered healthy behavior for all people that, when present, mitigates against personal powerlessness and results in personal empowerment. Nursing has determined that assertive behavior among its practitioners is an invaluable component for successful professional practice. As nurse works in different situations, they have to be assertive in order to meet the challenges and to win the cooperation from others.

\section{References}

1. Ann Mariner Tomey's. Guide to Nursing management. 7th ed., Philadelphia: Mosby company; 2002.

2. Bassie C. Leadership roles and management functions in nursing. 3rd ed., London: Lippincott publication; 2004.

3. Basavanthappa BT. Nursing administration. 3rd ed., New Delhi: Jaypee publication; 2014.

4. Cohen EL. Nursing case management. 4th ed., United Kingdom: Mosby Publication; 2004.

5. Shwirian PM. Professionalization in nursing. 3rd ed., Philadelpia: Lippincott Publishers; 2006.

6. Sankaranarayanan S. Learning and teaching in nursing. 1st ed., Mangaluru: Saunders Company; 2006.
7. Kumari's N. A textbook of management of nursing services and education. New Delhi: PV Publications; 2009.

8. Blackwell. Assertiveness among professional nurse. J Nurs Practice 2007;15(4):12-16.

9. Deltisidou A. Assertiveness in undergraduate nursing students. J Profess Assertive 2007;22(2):55-56.

10. Kang MJ, Lee $\mathrm{H}$. Assertiveness training on communication related factors and personnel turnover rate among hospital nurses. J Assertive 2006;20(2):34-36. DOI: 10.4040/jkan.2006.36.5.681.

11. Lin YR. Evaluate the assertiveness training for psychiatric patients. $J$ Eval Manage 2006;45(1):67-73.

12. Mahmoud AS, Al-Kalaldeh MT, Abed Elrahman M. The effect of assertiveness training program on jordanian nursing students' assertiveness and self-esteem. Inter J Nurs Pract Educ 2013;12(4): 14-16.

13. Mushtaq B. Assertiveness in Nursing. COJ Nursing \& Healthcare 2018;3(3):272.

14. Larijani TT, Aghajani M, Zamani N, et al. Assertiveness and the factors affecting it among nursing students of Tehran University of Medical Sciences. Int J New Technol Res 2017;3(5):34-38.

15. Miller R. Assertiveness in nursing students. Spring 2015;157.

16. Deltsidou A. Undergraduate nursing students' level of assertiveness in Greece: A questionnaire survey. Nurse education in practice 2008;9(5):322-330. 